\title{
Detection of antibodies of the IgM class in sera of patients recently infected with influenza viruses
}

\author{
YVONNE I. BUCHNER, R. B. HEATH, J. V. COLLINS, AND J. R. PATTISON \\ From the Joint Departments of Virology of the Medical Colleges of the London Hospital and \\ St. Bartholomew's Hospital, London
}

SYNOPSIS Sucrose density gradient ultracentrifugation can be used to detect specific $19 \mathrm{~S}$ antibodies of the IgM class in the sera of patients recently infected with influenza A virus, provided steps are taken to remove non-specific inhibitors of haemagglutination. The usefulness of the procedure for the diagnosis of influenza requires further evaluation.

The detection of antibodies of the IgM class in sera is proving to be a useful indicator of recent viral infection. This procedure has been of particular value for the diagnosis of rubella in pregnancy, where a variety of procedures have been used, including 2mercaptoethanol treatment (Banatvala et al, 1967), immunofluorescence (Cradock-Watson et al, 1972), sucrose density gradient ultracentrifugation (Desmyter et al, 1971), and gel chromatography (Pattison and Mace, 1975).

Specific IgM has been detected after recent natural infection with influenza $A$ virus by haemagglutination-inhibition following gel chromatography (Dobrovolskaya, 1971), radioimmunoassay (Daugharty et al, 1972), and immunofluorescence (Brown and O'Leary, 1973; De Silva et al, 1973; Urquhart, 1974). However, although specific IgM of the 19S class has been found by some workers (Dobrovolskaya, 1971; Daugharty et al, 1972) such specific IgM has been found to be exclusively of the $7 S$ type by others (Brown and O'Leary, 1973). Moreover, it has been reported that specific neutralizing antibody of the IgM class could not be detected in the serum of individuals given live influenza vaccine (Waldman et al, 1967).

In this study we have evaluated a sucrose density gradient method of fractionation followed by haemagglutination-inhibition tests for the detection of specific IgM antibodies against influenza $A$ virus.

\section{Material and Methods}

VIRUSES

The following strains of influenza $A$ virus were used: AiEngland/42/72

An inhibitor sensitive (A/Eng/72-S) and an inhibitor

Received for publication 28 October 1975 resistant variant of this strain (A/Eng/72-R) were employed. The latter was kindly supplied by $\mathrm{Dr}$ McCahon of the Wellcome Research laboratories. A/Port Chalmers/1/73 (A/PC/73)

All the viruses were propagated in fertile hens eggs.

SERA

Tests were first carried out on sera obtained from subjects (1-4) who were known not to have had an influenza $\mathrm{A}$ infection within the previous six months but who had high haemagglutination-inhibition (HI) titres against both $\mathrm{A} / \mathrm{Eng} / 72$ and $\mathrm{A} / \mathrm{PC} / 73$ viruses. One serum (No. 1) was obtained from a subject who had shown constant high titres of HI activity since an infection with A/Eng/72 28 months previously. The remaining sera (Nos. 2, 3, and 4) were obtained from three students at the end of a respiratory viral surveillance study carried out between October 1973 and April 1974. Sera from these subjects had shown unchanging high $\mathrm{HI}$ titres against $\mathrm{A} / \mathrm{PC} / 73$ during this period.

Tests were also carried out on 17 sera from eight patients (5-12) with a recent history of acute respiratory tract infection. In each instance recent influenza A virus infection had been diagnosed by virus isolation or a rise in either $\mathrm{HI}$ or complement fixing antibody titres, or a combination of these.

\section{HAEMAGGLUTINATION-INHIBITION TESTS}

Influenza $\mathrm{HI}$ tests were carried out in microplates using $0.5 \%$ chick erythrocytes and four haemagglutinating doses of virus. Sera were pretreated with receptor destroying enzyme (RDE) and absorbed with chick erythrocytes before titration. These procedures were omitted when fractions were assayed.

Rubella HI tests were performed according to the method of Ronalds et al (1975) using kaolin pretreatment and $0.5 \%$ pigeon erythrocytes as indicator. 
DENSITY GRADIENT CENTRIFUGATION

The procedure of Desmyter et al (1971) was used. Gradients were prepared by layering $1.5 \mathrm{ml}$ amounts of $40 \%, 25 \%$, and $10 \%(w / v)$ solutions of sucrose in phosphate buffered saline (PBS) into $5.5 \mathrm{ml}$ polycarbonate tubes which were equilibrated overnight at $4^{\circ} \mathrm{C} .0 .5 \mathrm{ml}$ samples of sera pretreated as described above were layered onto the gradients which were then centrifuged at $35000 \mathrm{rpm}(134000 \mathrm{~g})$ for 18 hours in an MSE Superspeed 50 with a $3 \times 5.5 \mathrm{ml}$ swing-out rotor. After centrifugation six fractions of $0.8 \mathrm{ml}$ were removed by puncturing the bottom of the tube, and influenza $\mathrm{HI}$ titres were determined.

\section{MERCAPTOETHANOL TREATMENT}

The effect of sulphydryl reduction on the antibody titres of these sera was tested by incubation of $0.6 \mathrm{ml}$ volumes of the fractions with $0.1 \mathrm{ml}$ of $0.5 \mathrm{M} \mathrm{2-}$ mercaptoethanol (2-ME) in a water-bath at $37^{\circ} \mathrm{C}$ for one hour. Influenza $\mathrm{HI}$ tests were performed on the resulting solutions without further treatment.

\section{IMMUNOGLOBULIN CONCENTRATIONS}

Immunoglobulin concentrations were established by means of radial immunodiffusion using plates and standards of declared concentration (Hoechst Pharmaceuticals, Hounslow, Middlesex).

\section{Results}

The sucrose density gradient method used in these studies is that currently used in our laboratory for the detection of specific rubella IgM antibodies. Figure 1A shows the results of assay of total IgM and total IgG after fractionation of the serum from patient 1. IgM was present in fractions 1-3 with a peak in fraction 2. IgG was present in fractions 3-5 with a peak in fraction 4. These results are in agreement with the original findings of Desmyter et al (1971), who conclude that antibody activity found in fraction 2 represented specific IgM, and antibody found in fraction 4 represented specific IgG. Patient 1 had no recent history of rubella, and in accordance with this specific activity against rubella was confined to the fractions containing IgG. Moreover, pretreatment of the serum with RDE had no effect on the inhibitory activity (fig 1B).

TESTING OF SERA FROM SUBJECTS WITHOUT RECENT INFLUENZA A INFECTION

With the density gradient technique used here, nonspecific inhibitors of rubella $\mathrm{HI}$ are recovered exclusively from the top of the gradient (Desmyter et $a l, 1971)$. In contrast to rubella, our results show that when detecting specific influenza antibody after fractionation, non-specific inhibitors interfere much

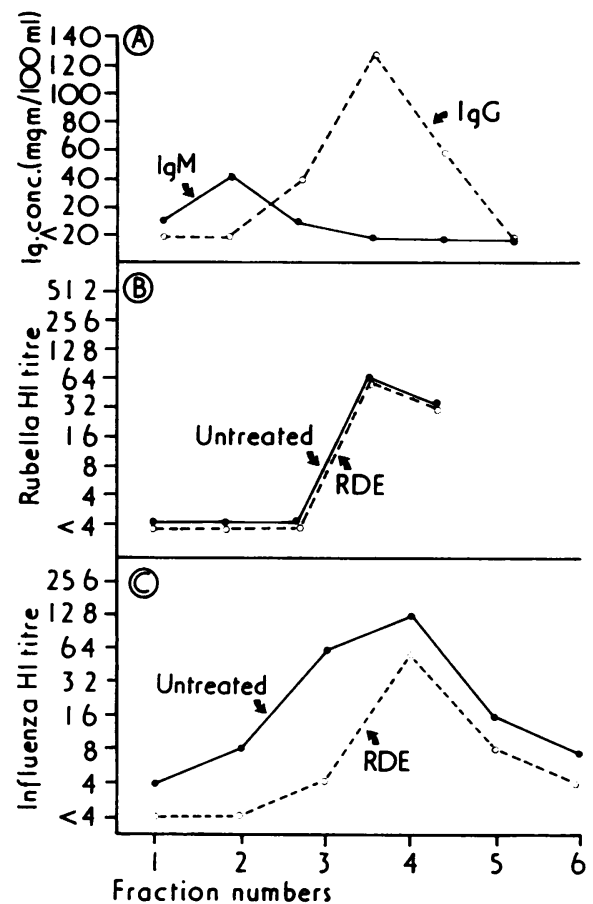

Fig 1 Sucrose density gradient fractionation of a serum obtained from a subject (No. 1) without evidence of recent infection with either influenza $A$ or rubella. $(A)$ Total IgM and total IgG concentrations. (B) HI titres against rubella. (C) HI titres against influenza A/PC/73.

more extensively. Figure $1 \mathrm{C}$ shows that in the serum obtained from a subject without evidence of recent $\overline{ }$ infection with influenza $A$ virus inhibitory activity was detected in all fractions after centrifugation. $\delta$ Moreover, influenza $\mathbf{A}$ inhibitory activity was found in fraction 2 after centrifugation of the other three음 sera with high $\mathrm{HI}$ titres from patients who had not $>$ had influenza within the previous six months (table을. I).

Some of the inhibitory activity must be due to the

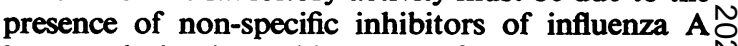
haemagglutination. This was confirmed by the find- $-\omega$ ing that when all the sera from patients who had not had recent influenza were treated with $\mathrm{RDE}$ beforeo fractionation, inhibitory activity to $\mathrm{A} / \mathrm{PC} / 73$ was $\frac{\overline{\mathbb{}}}{\mathbb{2}}$ removed from the early fractions known to contain? the high molecular weight immunoglobulins. It was $\square$ also noted that pretreatment of sera with RDE reduced the $\mathrm{HI}$ activity of the fractions which con- $\mathbb{D}$ tained the low molecular weight immunoglobulins $\frac{\mathbb{Q}}{\mathbb{Q}}$ (figs $1 \mathrm{C}$ and $2 \mathrm{~A}$ ).

When the fractions were tested with both inhibitor sensitive and inhibitor resistant strains of the A/Eng/응 


\begin{tabular}{|c|c|c|c|c|c|}
\hline \multirow[t]{3}{*}{ Subject No. } & \multirow{3}{*}{$\begin{array}{l}\text { Days after } \\
\text { Onset Serum } \\
\text { taken }\end{array}$} & \multicolumn{4}{|c|}{ Haemagglutination-inhibition Titres v. A/PC/73 } \\
\hline & & \multicolumn{2}{|c|}{ Whole Serum } & \multicolumn{2}{|l|}{ Fraction 2} \\
\hline & & Untreated & $R D E$ treated & Untreated & $R D E^{1}$ \\
\hline $\begin{array}{l}1 \\
2 \\
3 \\
4\end{array}$ & $\begin{array}{l}>365 \\
>180 \\
>180 \\
>180\end{array}$ & $\begin{array}{r}2048 \\
512 \\
512 \\
512\end{array}$ & $\begin{array}{r}1024 \\
256 \\
256 \\
128\end{array}$ & $\begin{array}{l}8 \\
8 \\
4 \\
8\end{array}$ & $\begin{array}{l}\mathbf{0} \\
\mathbf{0} \\
\mathbf{0} \\
\mathbf{0}\end{array}$ \\
\hline
\end{tabular}

Table I Sucrose density gradient fractionation of sera from individuals without evidence of recent infection with influenza $A$ virus

${ }^{1}$ The sera were pretreated with RDE before fractionation.

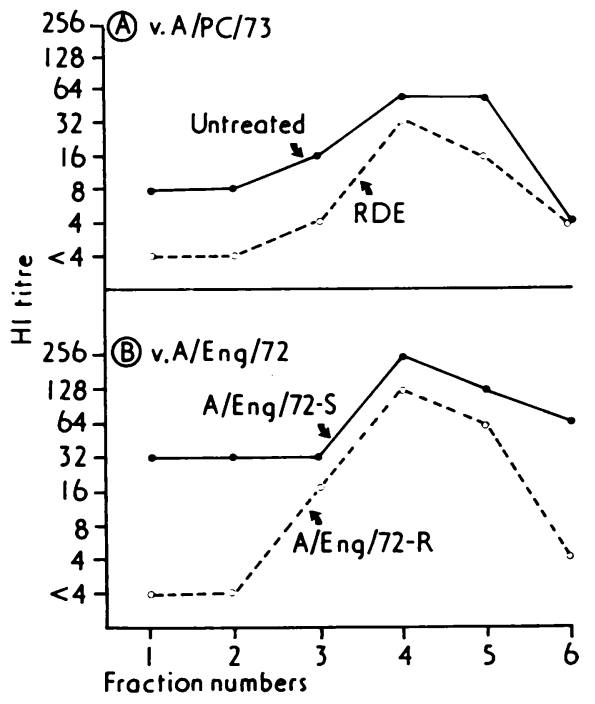

Fig 2 Sucrose density gradient fractionation of a serum obtained from a subject (No. 2) without evidence of recent infection with influenza $A$.

72 virus, inhibitory activity was detected in the early fractions by the inhibitor sensitive strain but not by the resistant strain (fig $2 \mathrm{~B}$ ). This again suggests that the inhibitory activity in these early fractions is due to the presence of non-specific inhibitors. It will be seen that $\mathrm{HI}$ activity is reduced in all fractions when tested against the inhibitor resistant strain.

\section{TESTING OF SERA FROM PATIENTS RECENTLY} INFECTED WITH INFLUENZA A

The above results show that to detect specific high molecular weight antibody against influenza $A$ it is essential to remove non-specific inhibitors of haemagglutination in the serum by means of treatment with RDE, or to employ inhibitor resistant strains of virus for estimating $\mathrm{HI}$ activity in the fractions.

Typical results obtained with a serum from a patient recently infected with influenza $A$ are shown in figure 3. Inhibitory activity to $\mathrm{A} / \mathrm{PC} / 73$ was still detectable in fraction 2 after pretreatment with RDE, which suggests that it was antibody mediated. It was again observed that pretreatment with RDE reduced $\mathrm{HI}$ activity in all fractions. Inhibitory activity was also found in fraction 2 when this was tested with the inhibitor resistant as well as the inhibitor sensitive strain of $A / E n g / 72$. This again suggests that the inhibitory activity in fraction 2 was antibody mediated. The inhibitory titre of all fractions was lower against the inhibitor resistant strain than against the inhibitor sensitive strain.

The potential diagnostic value of sucrose density gradient fractionation of sera pretreated with RDE is suggested by the results given in table II. Sera from all patients who had recently been infected with influenza A virus showed RDE resistant specific inhibitory activity in fraction 2 . All such activity in fraction 2 was found to be sensitive to $2-\mathrm{ME}$ whereas

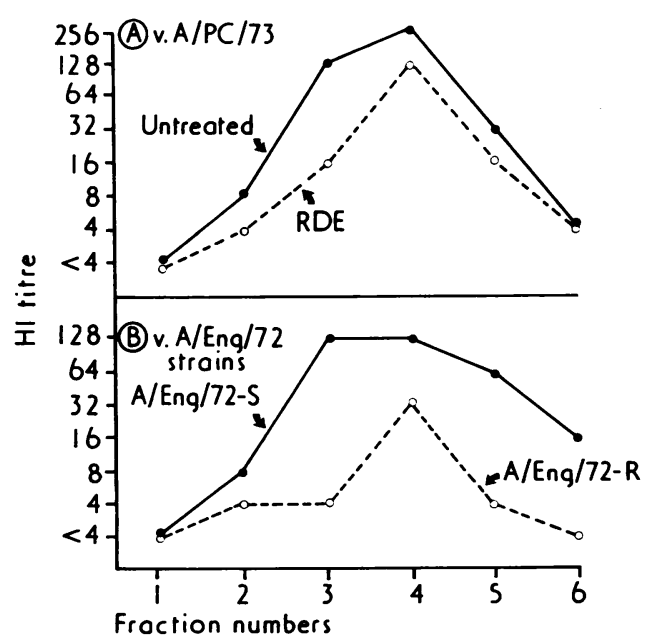

Fig 3 Sucrose density gradient fractionation of a serum obtained from a patient who had been infected with influenza A two weeks previously. 


\begin{tabular}{|c|c|c|c|c|c|}
\hline \multirow[t]{3}{*}{ Patient } & \multirow{3}{*}{$\begin{array}{l}\text { Days after } \\
\text { Onset }\end{array}$} & \multicolumn{4}{|c|}{ Haemagglutination-inhibition Titres v. A/PC/73 } \\
\hline & & \multicolumn{2}{|c|}{ Whole Serum } & \multicolumn{2}{|l|}{ Fraction 2} \\
\hline & & Untreated & $R D E$ treated & Untreated & $R D E^{1}$ \\
\hline \multirow[t]{2}{*}{5} & 14 & 512 & 512 & 8 & 4 \\
\hline & 150 & 512 & 256 & 8 & 0 \\
\hline \multirow[t]{6}{*}{6} & 15 & 8192 & 2048 & 64 & 32 \\
\hline & 28 & - & 1024 & - & 16 \\
\hline & 58 & - & 512 & - & 8 \\
\hline & 86 & - & 512 & - & 4 \\
\hline & 112 & - & 512 & - & 4 \\
\hline & 133 & 128 & 64 & 4 & 0 \\
\hline \multirow[t]{2}{*}{7} & 15 & - & 4096 & - & 4 \\
\hline & 26 & $>16000$ & 8192 & 32 & 4 \\
\hline 8 & 12 & 1024 & 256 & 16 & 4 \\
\hline 9 & 23 & 2048 & 512 & 32 & 4 \\
\hline \multirow[t]{2}{*}{10} & 2 & - & 128 & - & 4 \\
\hline & 28 & 2048 & 512 & 32 & 8 \\
\hline 11 & 15 & - & 512 & - & 4 \\
\hline \multirow[t]{2}{*}{12} & 7 & - & 64 & - & 4 \\
\hline & 15 & - & 4096 & - & 8 \\
\hline
\end{tabular}

Table II Sucrose density gradient fractionation of sera from patients recently infected with influenza $A$ virus

'The sera were pretreated with RDE before fractionation.

the titres of RDE resistant influenza $\mathrm{HI}$ activity in fraction 4 were unaffected by $2-\mathrm{ME}$.

In one patient (No. 6) specific HI activity was present in fraction 2 up to 112 days after the onset but was not detectable in a serum taken 133 days after the onset. In another patient (No. 5) no specific $\mathrm{HI}$ activity could be detected in fraction 2 of a serum taken 150 days after the onset although it could be detected in a serum taken 14 days after the onset of the acute infection (table II).

\section{Discussion}

Extensive studies in animals, including man, have shown that the primary humoral response to antigenic stimulation results in the production of high molecular weight immunoglobulins predominantly of the IgM class, which are progressively replaced by low molecular weight immunoglobulins of the IgG class (Uhr and Finkelstein, 1963; Svehag and Mandel, 1964; Cowan and Trautman, 1965). Detection of the presence of specific high molecular weight immunoglobulins is now a well established means of diagnosing recent infection with rubella virus (Banatvala et al, 1967; Desmyter et al, 1971; Cradock-Watson et al, 1972; Pattison and Mace, 1975).

This study shows that the confirmation of recent influenza infection on the basis of the presence of specific high molecular weight $\mathrm{HI}$ antibody is complicated by the presence of inhibitory activity in all fractions after sucrose density gradient centrifugation, even with sera from persons who have not had a recent influenza infection. Some of this activity is sensitive to RDE. With sera from patients without aơ recent influenza infection all the high molecularo weight $\mathrm{HI}$ activity is removed by RDE. Treatment? with RDE also causes a consistent slight reduction in the influenza $\mathrm{HI}$ activity of the IgG containing fractions although it has no effect on the rubella HIه activity of these same fractions. This suggests that inhibition of influenza virus haemagglutination by을 untreated sera is a complex phenomenon involving antibody, non-specific inhibitors, and possibly cofactors. We have also noted with the recent strains of influenza virus used here that the high molecularo weight non-specific factors are present in all sera fromo persons exposed to these viruses up to two years previously but are absent from the sera of personso who have never been exposed (unpublished observations). This is perplexing and requires furthero investigation.

With sera from patients recently infected with influenza A virus, high molecular weight inhibitoryn activity was still detected even after pretreatment with RDE, and when inhibitor resistant strains were used Such activity was not found in the sera of those whow had not recently been infected. This strongly suggests that influenza virus infection induces the productiono of $19 \mathrm{~S}$ antibodies of the IgM class. This conclusion isD supported by the finding that this high molecular: weight inhibitory activity is destroyed by $2-\frac{0}{0}$ mercaptoethanol.

Specific JgM antibodies against influenza viruses have previously been demonstrated by immuno $\mathbb{2}$ fluorescence procedures in the sera of patient\$ recently infected with influenza virus (De Silva et al 1973; Urquhart, 1974). However, using immunoz 
fluorescence, Brown and O'Leary (1973) found that, in naturally infected individuals all the specific influenza antibody with IgM specificity was of the $7 \mathrm{~S}$ type. The results described here are more in accord with those of Dobrovolskaya (1971) who detected specific IgM of the $19 \mathrm{~S}$ type in recently infected individuals using a gel chromatography procedure followed by influenza HI tests. However, in vaccinated individuals, Waldman et al (1967) failed to find any specific 19S IgM using a gel filtration technique followed by neutralization tests.

The reasons for the difference between the results described here and those of some of the other investigations are obscure. However, it is noted that the RDE resistant 2-ME sensitive high molecular weight activity found in association with recent infection in this study is of very low titre. Therefore variations in techniques used for removal of nonspecific inhibitors and/or in the sensitivity of the antibody assay system used may explain the failure to detect such activity in other investigations.

Further evaluation of the procedure described here for the diagnosis of recent influenza will require its extension to a large number of individuals with and without evidence of recent infection. Preliminary results of an investigation of this kind have been encouraging (Buchner et al, in preparation).

We wish to thank the Chest and Heart Association for a grant for the equipment for this study and the Joint Research Board of St. Bartholomew's Hospital Medical College and the North East Thames Regional Health Authority Research Committee for support.

\section{References}

Banatvala, J. E., Best, J. M., Kennedy, E. A., Smith, E. E., and Spence, M. E. (1967). A serological method for demon- strating recent infection by rubella virus. Brit. med. J., 3, 285-286.

Brown, G. C. and O'Leary, T. P. (1973). Fluorescent antibodies to influenza virus in various immunoglobulin fractions of serum after natural infection or vaccination. J. Immunol., 110, 889-896.

Cowan, K. M. and Trautman, R. (1965). Antibodies produced by guinea pigs infected with foot-and-mouth disease virus. J. Immunol., 94, 858-867.

Cradock-Watson, J. E., Bourne, M. S., and Vandervelde, E. M. (1972). IgG, IgA and IgM responses in acute rubella determined by the immunofluorescent technique. $J$. Hyg . (Camb.), 70, 473-485.

Daugharty, H., Davis, M. L., and Kaye, H. S. (1972). Immunoglobulin class of influenza antibodies investigated by radioimmunoassay (RIA). J. Immunol., 109, 849-856.

De Silva, L. M., Khan, M. S., Kampfner, G., Tobin, J. O'H., Gilbert, R., and Morris, C. A. (1973). The post-mortem diagnosis of influenzal infection by fluorescent IgG, IgA and IgM antibody studies on necropsy blood. J. Hyg. (Camb.), 71, 107-112.

Desmyter, J., South, M. A., and Rawls, W. E. (1971). The IgM antibody response in rubella during pregnancy.J. med. Microbiol., 4, 107-114.

Dobrovolskaya, N. G. (1971). Formation of antibodies of different classes in influenzal infections. J. Hyg. Epidem. (Praha.), 15, 148-155.

Pattison, J. R. and Mace, J. E. (1975). The detection of specific IgM antibodies following infection with rubella virus. J. clin. Path., 28, 377-382.

Ronalds, C. J., Doherty, N., Pattison, J. R., and Heath, R. B. (1975). A comparative study of methods used for removing non-specific inhibitors of rubella haemagglutination from human sera. Med. Lab. Technol., 32, 317-320.

Svehag, S. E. and Mandel, M. (1964). The formation and properties of poliovirus neutralising antibody. I 19S and 7S antibody formation: differences in kinetics and antigen dose requirement for induction. J. exp. Med., 119, 1-19.

Uhr, J. W. and Finkelstein, M. S. (1963). Antibody formation. IV. Formation of rapidly and slowly sedimenting antibodies and immunological memory to bacteriophage $\phi \chi 174 . J . \exp$. Med., 117, 457-477.

Urquhart, G. E. D. (1974). Serum IgM and IgA responses in influenza A infections. J. clin. Path., 27, 198-201.

Waldman, R. H., Kasel, J. A., Alford, R. H., and Mann, J. J. (1967). Immunoglobulin classes of serum neutralising antibody formed in response to infection with human $\mathbf{A}_{2}$ influenza virus. Proc. Soc. exp. Biol. (N.Y.), 125, 316321. 